\title{
CT scanning in blunt chest trauma: validation of decision instruments
}

\section{Tomografia computadorizada em trauma torácico fechado: validação de instrumentos de decisão}

Gabriel Sebben Reichardi ${ }^{1}$ (iD; Gabriel Mondin Nogueira ${ }^{1}$; Leonardo Krieger Rafaeli; Paulo Roberto Soltoski ${ }^{1,2}$; Silvania Klug PIMENTEL, TCBC-PR ${ }^{1,2}$.

\begin{abstract}
A B S T R A C T
Objective: to perform an external validation of two clinical decision instruments (DIs) - Chest CT-All and Chest CT-Major - in a cohort of patients with blunt chest trauma undergoing chest CT scanning at a trauma referral center, and determine if these Dls are safe options for selective ordering of chest CT scans in patients with blunt chest trauma admitted to emergency units. Methods: cross-sectional study of patients with blunt chest trauma undergoing chest CT scanning over a period of 11 months. Chest CT reports were cross-checked with the patients' electronic medical record data. The sensitivity and specificity of both instruments were calculated. Results: the study included 764 patients. The Chest CT-All DI showed $100 \%$ sensitivity for all injuries and specificity values of $33.6 \%$ for injuries of major clinical significance and $40.4 \%$ for any lesion. The Chest CT-Major DI had sensitivity of $100 \%$ for injuries of major clinical significance, which decreased to $98.6 \%$ for any lesions, and specificity values of $37.4 \%$ for injuries of major clinical significance and $44.6 \%$ for all lesions. Conclusion: both clinical DIs validated in this study showed adequate sensitivity to detect chest injuries on CT and can be safely used to forego chest CT evaluation in patients without any of the criteria that define each DI. Had the Chest CT-All and Chest CT-Major DIs been applied in this cohort, the number of CT scans performed would have decreased by $23.1 \%$ and $24.6 \%$, respectively, resulting in cost reduction and avoiding unnecessary radiation exposure.
\end{abstract}

Keywords: Tomography. Thorax. Thoracic Injuries. Wounds, Nonpenetrating. Sensitivity and Specificity.

\section{INTRODUCTION}

T he use of computed tomography (CT) imaging in blunt trauma has increased exponentially in trauma centers around the world, particularly over the past two decades ${ }^{1,2}$. The high accuracy of this method in identifying lesions undetected on clinical examination has allowed for faster and more efficient management of the patients ${ }^{3-6}$ to the point that secondary investigation based on whole-body CT (pan scan) has become common in the evaluation of hemodynamically stable patients with blunt trauma7,8. However, several studies have indicated that the increased use of CT scanning is directly related to real and quantifiable risks to the patient due to exposure to ionizing radiation ${ }^{9-11}$, in addition to increasing hospital costs and prolonging patient stay in emergency units $^{10}$.
A single chest CT scan exposes the patient to an amount of radiation similar to that of 117 chest X-rays ${ }^{9}$. Estimates suggest that the practice of ordering chest $C T$ after a normal chest X-ray may induce a new case of cancer for every 108 chest injuries diagnosed in women and every 231 chest injuries diagnosed in men ${ }^{10}$. Also, $1.5-2.0 \%$ of all cases of cancer in the United States are estimated to be related to radiation from CT scanning ${ }^{11}$. Therefore, judicious use of CT scanning is crucial.

In a recent study published in PLOS Medicine, a group of researchers developed and validated two clinical decision instruments (DIs) - NEXUS Chest CTAll and NEXUS Chest CT-Major - which rules out, with high sensitivity, the presence of clinically significant chest injuries in patients with blunt chest trauma. These instruments are based on a list of clinical criteria that must be evaluated during the initial assessment of a

1 - Universidade Federal do Paraná, Curso de Medicina - Curitiba - PR - Brasil 2 - Hospital do Trabalhador, Departamento de Cirurgia Geral - Curitiba - $P R$ - Brasil 
blunt thoracic trauma victim. If none of the listed criteria is present, the physician can safely forego CT scanning, since the possibility of this exam to show a chest injury is extremely small. The criteria to be evaluated in each of the decision instruments, according to the original article, are:
NEXUS Chest CT-All

Chest wall tenderness

Sternum tenderness

Scapular tenderness

Thoracic spine tenderness

Distracting injury

Rapid deceleration mechanism

Abnormality in chest $\mathrm{x}$-ray
NEXUS Chest CT-Major

Chest wall tenderness

Sternum tenderness

Scapular tenderness

Thoracic spine tenderness

Distracting injury

Abnormality in chest $x$-ray
The first instrument, NEXUS Chest CT-All, has great sensitivity for all thoracic injuries. The second, NEXUS Chest CT-Major, has great sensitivity only for injuries of major clinical significance, accepting a small margin of error, therefore allowing greater specificity. The application of these instruments can reduce unnecessary chest CTs by $25-37 \%$ in patients with blunt chest trauma ${ }^{12}$.

The aim of the present study was to perform an external validation of both NEXUS Chest CT Dls, estimating the accuracy of the instruments in a cohort of patients at a trauma referral center. Confirmation of the external validity and high sensitivity of these instruments will broaden their evidence-based applicability in emergency centers worldwide, contributing to a substantial reduction in requests for CT scans in patients who do not benefit from this evaluation.

\section{METHODS}

This cross-sectional study was conducted at Hospital do Trabalhador, a referral center for trauma care in the city and metropolitan region of Curitiba (Parana). The protocol of the study was approved by the Ethics Committee of the institution under the protocol number 07533519.8.0000.5225.

The analysis included all electronic medical records of patients admitted to the emergency unit of the hospital who underwent chest CT during an 11-month period from September 1, 2018, to July 31, 2019.

Two thousand and ninety-one chest CT records were found during the study period and were cross- checked with the patients' electronic medical record data. Patients were included when having: (1) blunt chest trauma, (2) age above 18 years, (3) Glasgow Coma Scale score $>12$ on admission, and (4) chest X-ray obtained before CT scanning. Patients not meeting the inclusion criteria or whose records were considered to have insufficient information were excluded. The final analysis included 764 patients.

The 16-channel Bright Speed GE tomograph is used at Hospital do Trabalhador. Only official reports signed by a radiologist were accepted to define the presence of thoracic injury on $\mathrm{CT}$. In reports with vague information (e.g., possible pulmonary contusion), a thoracic injury was considered to be present. The CT findings included in the analysis were those considered in the original study that defined both Dls, namely, pneumothorax, hemothorax, multiple rib fracture, sternal fracture, pulmonary contusion, thoracic spine fracture, scapular fracture, great vessel injury, diaphragm rupture, mediastinal or pericardial hematoma, esophageal injury, bronchial or tracheal injury, and pneumomediastinum. These findings were further categorized into injuries of major or minor clinical significance according to the management of each case, as defined in the original study.

The analyzed variables included age, sex, and CT findings, in addition to the seven criteria that make up de Dls, namely, (1) presence of abnormality on chest X-ray performed on admission, (2) rapid deceleration mechanism associated with the trauma, (3) distracting injuries, and tenderness on palpation of the (4) chest wall, (5) sternum, (6) scapula, and (7) thoracic spine. 
The absence of these criteria altogether indicated a likely absence of injury on chest CT.

Rapid deceleration was defined as any highenergy trauma involving a deceleration mechanism, for example, a motor vehicle accident against a partition at speed above $60 \mathrm{~km} / \mathrm{h}$, or a fall from an elevation greater than six meters. In the absence of accurate information, deceleration mechanisms described in the medical record with terms like "high energy" and "high impact" were considered to be associated with rapid deceleration. Distracting injuries included any extrathoracic injury considered (and described in the medical record) by the physician to be sufficiently relevant to divert attention and compromise the validity of the clinical examination, such as long bone fracture and degloved limbs.

Patients with at least one of the seven DI criteria were considered to have a positive DI screening result. The patients were further divided into four groups, as follows:

- True-positive: positive DI screening result and injury on chest $\mathrm{CT}$.

- True-negative: negative DI screening result and no injury on chest CT.

- False-positive: positive DI screening result and no injury on chest CT.

- False-negative: negative DI screening result and injury on chest $\mathrm{CT}$.

This categorization was performed for both DIs. The sensitivity, specificity, positive predictive value (PPV), and negative predictive value (NPV) of the Dls were then calculated based on these data.

\section{Statistical analysis}

The data are represented as percentages and medians ( \pm standard deviations). The relationship between the presence of chest injury and each of the clinical criteria that make up the Dls was evaluated. As a measure of effect, the odds ratio (OR) with a 95\% confidence interval $(\mathrm{Cl})$ was used. The statistical significance was evaluated using Pearson's chi-square test to control for possible confounding variables, considering $p$ values $<0.05$ as significant.

\section{RESULTS}

The study included 764 patients, of whom $77.2 \%(n=590)$ were males. The age of the patients ranged from 18 to 97 years (mean 43.9 17.9 years) (Table 1). The most prevalent mechanisms of trauma were truck and car accidents $(21.7 \%, n=166)$, motorcycle accidents $(20 \%, n=153)$, and elevated falls $(17.7 \%, n=135)$ (Table 2).

Table 1. Epidemiological data.

\begin{tabular}{lccc}
\hline Variable & Male & Female & Total \\
\hline $\begin{array}{l}\text { N (\%) } \\
\begin{array}{l}\text { Mean age } \\
( \pm \text { SD })\end{array}\end{array}$ & $590(77.2)$ & $174(22.8)$ & $764(100)$ \\
\hline SD: standard deviation. & $41.6 \pm 15.9$ & $51.7 \pm 21.8$ & $43.9 \pm 17.9$ \\
\hline
\end{tabular}

Table 2. Trauma mechanisms.

\begin{tabular}{lcc}
\hline Trauma Mechanisms & N & $\%$ \\
\hline Motor vehicle accident - car & 166 & 21.7 \\
Motor vehicle accident - motorcycle & 153 & 20 \\
Elevated fall & 135 & 17.7 \\
Same level fall & 110 & 14.4 \\
Physical agression & 96 & 12.6 \\
Pedestrian accident & 48 & 6.3 \\
Others & 56 & 7.3 \\
\hline
\end{tabular}

Chest CT images showed injuries of major clinical significance in 20 patients (2.6\%) and injuries of minor clinical significance in $125(16.4 \%)$ of them. The most frequent injuries included fracture of two or more ribs ( $n=119)$, hemothorax $(n=43)$, pulmonary contusion $(n=37)$, and pneumothorax $(n=36)$ (Tables 3 and 4$)$.

The Chest CT-All DI showed sensitivity and NPV rates of $100 \%$ for injuries of major clinical significance and any injury since none of the 764 patients in the study had a false-negative result. The specificity of this instrument was $33.6 \%$ for lesions of major clinical significance and $40.4 \%$ for all lesions. The low specificity reflects a large number of false-positive results $(n=369)$.

The Chest CT-Major DI also had sensitivity and NPV rates of $100 \%$ for injuries of major clinical significance, but for injuries of minor or major clinical 
significance, the sensitivity decreased to $98.6 \%$ and the NPV decreased to $99.3 . \%$. This DI yielded two falsenegative results. The first was in a 44-year-old man and the second was in a 50-year-old man. Both presented pulmonary contusion on imaging evaluation. The first was released on the first day after receiving care, and the second remained hospitalized for 2 days for observation. The specificity of this instrument was $37.4 \%$ for lesions of major clinical significance and $44.6 \%$ for all lesions.

Table 3. Injuries of major clinical significance..

\begin{tabular}{|c|c|c|}
\hline Injury & $\mathrm{N}$ & $\%$ \\
\hline Pneumothorax: received CTD & 15 & 42.9 \\
\hline Hemothorax: received CTD & 8 & 22.9 \\
\hline $\begin{array}{l}\text { Fracture of two or more ribs: required } \\
\text { surgical intervention }\end{array}$ & 4 & 11.4 \\
\hline $\begin{array}{l}\text { Sternal fracture: required surgical } \\
\text { intervention }\end{array}$ & 1 & 2.9 \\
\hline $\begin{array}{l}\text { Thoracic spine fracture: required surgical } \\
\text { intervention }\end{array}$ & 2 & 5.7 \\
\hline Great vessel injury & 3 & 8.6 \\
\hline $\begin{array}{l}\text { Mediastinal or pericardial hematoma: } \\
\text { required CTD }\end{array}$ & 2 & 5.7 \\
\hline
\end{tabular}

CTD: chest tube drainage.

Table 4. Injuries of minor clinical significance.

\begin{tabular}{lcc}
\hline Injury & N & $\%$ \\
\hline $\begin{array}{l}\text { Pneumothorax: no CTD required, but } \\
\text { remained under observation for more } \\
\text { than } 24 \text { hours }\end{array}$ & 21 & 8.8 \\
$\begin{array}{l}\text { Hemothorax: no CTD required, but } \\
\text { remained under observation for more } \\
\text { than } 24 \text { hours }\end{array}$ & 35 & 14.6 \\
$\begin{array}{l}\text { Fracture of two or more ribs: no surgical } \\
\text { intervention required }\end{array}$ & 115 & 48.1 \\
$\begin{array}{l}\text { Sternal fracture: no surgical intervention } \\
\text { required }\end{array}$ & 15 & 6.3 \\
$\begin{array}{l}\text { Pulmonary contusion: remained under } \\
\text { observation for more than 24 hours }\end{array}$ & 37 & 15.5 \\
$\begin{array}{l}\text { Thoracic spine fracture: no surgical } \\
\text { intervention required }\end{array}$ & 6 & 2.5 \\
$\begin{array}{l}\text { Scapular fracture: no surgical intervention } \\
\text { required }\end{array}$ & 8 & 3.3 \\
$\begin{array}{l}\text { Mediastinal or pericardial hematoma: no } \\
\text { CTD required }\end{array}$ & 1 & 0.4 \\
$\begin{array}{l}\text { Tracheal injury: no surgical intervention } \\
\text { required }\end{array}$ & 1 & 0.4 \\
\hline CID: & & \\
\hline
\end{tabular}

CTD: chest tube drainage.
Patients in the true-negative group met no criteria at the initial clinical examination and would not otherwise have been evaluated with chest $\mathrm{CT}$. The percentage of true-negative results represents an estimate of the reduction in chest CT scans if the DIs were applied. This estimate considered only patients who underwent selective chest CT $(n=329,43 \%)$ and excludes those who underwent full-body CT scanning. In this cohort, the number of chest $\mathrm{CT}$ scans requested would have reduced by $23.1 \%$ with the Chest CT-All $\mathrm{DI}$ and by $24.6 \%$, with the Chest CT-Major DI, which had greater specificity (Table 5 ).

Each of the seven criteria that compose the DIs was also analyzed against the presence of the evaluated chest injuries (Table 6). Statistically significant $(p<0.05)$ associations were identified for abnormal chest X-ray and tenderness on palpation of the chest wall, sternum, and scapula. The odds of chest injury were, respectively, 144, 6, 2, and 15 times higher in patients meeting these criteria compared with those not meeting these criteria.

\section{DISCUSSION}

The relevance of CT scanning in the diagnosis of trauma injuries is well established ${ }^{3-6}$. However, the high radiation levels associated with this imaging method divide opinions about the need to recommend $\mathrm{CT}$ for all victims of blunt trauma ${ }^{9-11}$

Dls are important tools in clinical practice ${ }^{13,1} 4$. Based on objective and easily assessable clinical criteria, DIs help decide the best therapeutic approach. A wellknown example is the CURB-65 score, which recommends hospitalization for patients with community-acquired pneumonia based on five criteria ${ }^{15}$.

In order to predict the absence of chest injury on chest CT imaging based on clinical criteria, Rodriguez et al. ${ }^{12}$ developed and validated the DIs Chest CT-All and Chest CT-Major. These decision instruments identify, with high sensitivity, patients with blunt chest trauma without clinically relevant chest injury, thus safely foregoing chest CT scanning in these patients ${ }^{12}$.

In the present study, we performed an external validation of these two DIs, applying them retrospectively to patients admitted to a referral trauma hospital in a 
large city in Southern Brazil. In a cohort of 764 patients, the sensitivity of both DIs for this population was higher than the one reported in the original study describing both instruments.

Table 5. Performance of clinical decision instruments in the present external validation study.

\begin{tabular}{lcccccc}
\hline DI & Injury & Sensitivity (\%) & Specificity (\%) & NPV (\%) & PPV (\%) & $\begin{array}{c}\text { Reduction in CT } \\
\text { exams* }(\%)\end{array}$ \\
\hline Chest CT-All & $\begin{array}{c}\text { Injuries of } \\
\text { major clinical } \\
\text { significance } \\
\text { Any injury }\end{array}$ & 100 & 33.6 & 100 & 3.9 & 23.1 \\
$\begin{array}{l}\text { Chest CT- } \\
\text { Major }\end{array}$ & $\begin{array}{c}\text { Injuries of } \\
\text { major clinical } \\
\text { significance } \\
\text { Any injury }\end{array}$ & 100 & 40.4 & 100 & 28.2 & 24.06 \\
& 98.6 & 37.4 & 100 & 4.1 & \\
\hline
\end{tabular}

DI: clinical decision instrument; NPV: negative predictive value; PPV: positive predictive value; CT: computed tomography. * Estimated reduction for selective chest CT scans.

Table 6. Odds ratio $(O R)$ between clinical criteria and the presence of chest injury.

\begin{tabular}{lccc}
\hline Criterion & OR & $(95 \%) \mathrm{Cl}$ & $\mathrm{p}$ \\
\hline Sudden deceleration & 0.8 & $0.43-1.42$ & 0.41 \\
Abnormal chest X-ray & 143.5 & $50.9-404.2$ & $<0.0001$ \\
Distracting injury & 0.8 & $0.44-1.42$ & 0.43 \\
Tenderness on chest wall palpation & 5.9 & $3.77-9.23$ & $<0.0001$ \\
Tenderness on sternal palpation & 2.5 & $1.38-4.35$ & 0.002 \\
Tenderness on scapular palpation & 15.2 & $4.13-56.01$ & $<0.0001$ \\
Tenderness on thoracic spine palpation & 2.2 & $0.97-5.03$ & 0.056 \\
\hline
\end{tabular}

OR: odds ratio; Cl: confidence interval.

For the Chest CT-All DI, the sensitivity was $100 \%$ for all injuries compared with $99.2 \%$ for injures of major clinical significance and $95.4 \%$ for any injury in the original study. For Chest CT-Major, we found sensitivity of $100 \%$ for lesions of major clinical significance and $98.6 \%$ for any lesion compared with $99.2 \%$ and $90.7 \%$, respectively, in the original study.

Patients not meeting any of these DIs clinical criteria but presenting chest injury on $\mathrm{CT}$ imaging were considered to have a false-negative screening result. The main concern with the application of these Dls lies with these patients since their injuries would not have been diagnosed based on these instruments alone. However, we found only two false-negative results in our study. The first was a 44-year-old man with pulmonary contusion without chest tenderness who was released on the first day after receiving initial care. The second was a 50-year-old man, also with pulmonary contusion, who was hospitalized for observation as a result of worsening clinical condition with pain on inspiration. This patient was released two days later without intervention. The detection of pulmonary contusion by CT scan did not change the management or prognosis of these patients, so CT scanning could have been foregone in these cases.

The Chest CT-All DI had a high sensitivity for all lesions, while the Chest CT-Major DI had higher specificity, further reducing the use of $\mathrm{CT}$ at the cost of a small rate of false-negative results $(0.3 \%)$. Since the management of both patients with false-negative results was unaffected by the imaging test, we considered the Chest CT-Major DI to be preferable since its ability to reduce ordering of chest $\mathrm{CT}$ is considerably higher.

Rapid deceleration is known to be associated with thoracic aortic rupture ${ }^{16}$. A possible concern when choosing Chest CT-Major over Chest CT-All is that the criterion of the deceleration mechanism is absent in the 
former. The present study had three cases of aortic rupture, one of which was not associated with a deceleration mechanism. In all three cases, the patients presented another criterion - one had an abnormal chest X-ray, another had tenderness on thoracic spine palpation, and the third had a femoral fracture. Therefore, the absence of the criterion deceleration mechanism did not affect the DI results.

The results of the present study support the use of the Chest CT-All and Chest CT-Major DIs for a safe, evidence-based selection of patients with blunt chest trauma who do not benefit from advanced imaging, reinforcing the importance of the application of these DIs in emergency units worldwide. In addition to exempting the patient from the risks of exposure to ionizing radiation by avoiding $\mathrm{CT}$ scanning, these DIs could potentially spare substantial resources, given the high cost of advanced imaging. Had both DIs Chest CTAll and Chest CT-Major been applied to the patients evaluated in this study, the number of chest CT scans would have reduced by $23.1 \%$ and $24.6 \%$, respectively.

Some precautions inherent to these tools must be taken when using them. Once the patient presents any of the criteria, the decision instrument will no longer be useful, since the possibility of the patient presenting a thoracic injury is low, given the low specificity of the criteria. In addition, they can be used only in patients over 18 years of age, and a Glasgow Coma Scale $>12$ upon admission, which limits their applicability.

An important bias of this study is that some victims of blunt chest trauma are immediately submitted to tomography, without first undergoing a conventional radiography. One of the criteria of the decision instruments is the presence of an abnormality in chest $x$-ray. These patients were, therefore, excluded from the study. The main limitation of this article, however, is that it is a retrospective study. A prospective evaluation would bring more reliable data to the real applicability of the decision instruments. This, however, does not invalidate the results found here. The external validity determined in this study should encourage the use of NEXUS protocols in other trauma centres.

The seven criteria that make up these decision tools are simple, objective, and greatly relevant in the initial assessment of trauma patients. The estimated OR showed that patients with an abnormal chest $\mathrm{X}$-ray are 144 times more likely to have chest injuries compared with those with a normal chest $X$-ray. Tenderness on palpation of the chest wall, sternum, and scapula also showed a significant relationship with the presence of chest injury on $\mathrm{CT}$, and patients with palpation tenderness on one of these sites are 2 to 15 times more likely to have chest injury on CT. The remaining criteria had no significant relationship with the presence of chest injury on CT.

The initial clinical examination is crucial for the prognosis of trauma victims ${ }^{17}$. In the age of technology and progressively complex and expensive diagnostic examinations, one must not forget the basic principles of medicine. A CT scan should not replace a careful clinical examination.

\section{R E S U M O}

Objetivo: realizar validação externa de dois instrumentos de decisão clínica (IDCS) - TC de tórax-All e TC de tórax-Major - em uma coorte de pacientes com trauma torácico fechado submetidos a tomografia computadorizada de tórax em centro de referência para trauma, e determinar se esses IDCS são opções seguras para solicitação seletiva de tomografias computadorizadas de tórax em pacientes com trauma torácico fechado admitidos em unidades de emergência. Métodos: estudo retrospectivo transversal de pacientes com trauma torácico fechado submetidos a tomografia computadorizada de tórax, por período de 11 meses. Os laudos da TC de tórax foram cruzados com os dados do prontuário eletrônico dos pacientes. A sensibilidade e especificidade de ambos os instrumentos foram calculadas. Resultados: o estudo incluiu 764 pacientes. O IDC TC de tórax-All apresentou sensibilidade de 100\% para todas as lesões e especificidades de 33,6\% para lesões de maior significado clínico e 40,4\% para qualquer lesão. O IDC TC de tórax Major teve sensibilidade de 100\% para lesões de maior significado clínico, que diminuiu para 98,6\% para quaisquer lesões, e especificidades de 37,4\% para lesões de maior significado clínico e 44,6\% para todas as lesões. Conclusão: ambos os instrumentos de decisão clínica validados neste estudo mostraram sensibilidade adequada para detectar lesões torácicas na TC e podem ser usados com segurança para dispensar a avaliação da TC de tórax em pacientes sem nenhum dos critérios que definem o IDC. Se os IDCS TC de tórax-All e TC de tórax Major de tórax tivessem sido aplicados nesta coorte, o número de tomografias realizadas teria diminuído em $23,1 \%$ e $24,6 \%$, respectivamente, resultando em redução de custos e evitando exposição desnecessária à radiação.

Palavras chave: Tomografia. Tórax. Lesões Torácicas. Feridas Não Penetrantes. Sensibilidade e Especificidade. 


\section{REFERENCES}

1. Broder J, Warshauer DM. Increasing utilization of computed tomography in the adult emergency department, 2000-2005. Emerg Radiol. 2006;13(1):25-30.

2. Korley FK, Pham JC, Kirsch TD. Use of advanced radiology during visits to US emergency departments for injury-related conditions, 19982007. JAMA. 2010;304(13):1465-71.

3. Newbury A, Dorfman JD, Lo HS. Imaging and management of thoracic trauma. Semin Ultrasound CT. 2018;39(4):347-54.

4. Mokrane F, Revel-Mouroz P, Saint Lebes B, Rousseau $\mathrm{H}$. Traumatic injuries of the thoracic aorta: The role of imaging in diagnosis and treatment. Diag Interv Imaging. 2015;96(7-8):693-706.

5. American College of Surgeons. Advanced Trauma Life Support. 10th ed. Chicago (IL): American College of Surgeons; 2018.

6. Oikonomou A, Prassopoulos P. CT imaging of blunt chest trauma. Insights Imaging. 2011;2(3):281-95.

7. Lee WS, Parks NA, Garcia A, Palmer BJ, Liu TH, Victorino GP. Pan computed tomography versus selective computed tomography in stable, young adults after blunt trauma with moderate mechanism: a cost-utility analysis. J Trauma Acute Care Surg. 2014;77(4):527-33.

8. Weninger P, Mauritz W, Fridrich P, Spitaler R, Figl $M$, Kern $B$, et al. Emergency room management of patients with blunt major trauma: evaluation of the multislice computed tomography protocol exemplified by an urban trauma center. J Trauma Acute Care Surg. 2007;62(3):584-91.

9. Smith-Bindman R, Lipson J, Marcus R, Kim KP,
Mahesh M, Gould R, et al. Radiation dose associated with common computed tomography examinations and the associated lifetime attributable risk of cancer. Arch Intern Med. 2009;169(22):2078-86.

10. Rodriguez RM, Baumann BM, Raja AS, Langdorf $\mathrm{Ml}$, Anglin D, Bradley RN, et al. Diagnostic yields, charges, and radiation dose of chest imaging in blunt trauma evaluations. Acad Emerg Med. 2014;21(6):644-50.

11. Brenner DJ, Hall EJ. Computed tomography-an increasing source of radiation exposure. $\mathrm{N}$ Engl J Med. 2007;357(22):2277-84.

12. Rodriguez RM, Langdorf MI, Nishijima D, Baumann BM, Hendey GW, Medak AJ, et al. Derivation and validation of two decision instruments for selective chest $\mathrm{CT}$ in blunt trauma: a multicenter prospective observational study (NEXUS Chest CT). PLoS Med. 2015;12(10):e1001883

13. Green SM. When do clinical decision rules improve patient care? Ann Emerg Med. 2013;62(2):132-5.

14. Childs JD, Cleland JA. Development and application of clinical prediction rules to improve decision making in physical therapist practice. Phys Ther. 2006;86(1):122-31.

15. Lim WS, Van der Eerden M, Laing R, Boersma W, Karalus N, Town $G$, et al. Defining community acquired pneumonia severity on presentation to hospital: an international derivation and validation study. Thorax. 2003;58(5):377-82.

16. Neschis DG, Scalea TM, Flinn WR, Griffith BP. Blunt aortic injury. N Engl J Med. 2008;359(16):1708-16.

17. Bokhari F, Brakenridge S, Nagy K, Roberts R, Smith $R$, Joseph $K$, et al. Prospective evaluation of the sensitivity of physical examination in chest trauma. J Trauma Acute Care Surg. 2002;53(6):1135-8.
Received in: 31/05/2020

Accepted for publication: 27/08/2020

Conflict of interest: no.

Funding source: none.

\section{Mailing address:}

Gabriel Sebben Reichardt

E-mail: sebbenes@hotmail.com 